\title{
Biomechanical evaluation of the craniovertebral junction after unilateral joint-sparing condylectomy: implications for the far lateral approach revisited
}

\author{
Varun R. Kshettry, MD, ${ }^{1,2}$ Andrew T. Healy, MD, ${ }^{1,2}$ Robb Colbrunn, PhD, ${ }^{2}$ Dylan T. Beckler, BS, ${ }^{2}$ \\ Edward C. Benzel, MD, ${ }^{1,2}$ and Pablo F. Recinos, MD ${ }^{1,3}$ \\ ${ }^{1}$ Department of Neurological Surgery, Cleveland Clinic; ${ }^{2}$ Spine Research Lab, Lutheran Hospital, Cleveland Clinic Center for \\ Spine Health; and ${ }^{3}$ Section of Rhinology, Sinus and Skull Base Surgery, Head and Neck Institute, Cleveland Clinic, Cleveland, \\ Ohio
}

\begin{abstract}
OBJECTIVE The far lateral transcondylar approach to the ventral foramen magnum requires partial resection of the occipital condyle. Early biomechanical studies suggest that occipitocervical (OC) fusion should be considered if 50\% of the condyle is resected. In clinical practice, however, a joint-sparing condylectomy has often been employed without the need for OC fusion. The biomechanics of the joint-sparing technique have not been reported. Authors of the present study hypothesized that the clinically relevant joint-sparing condylectomy would result in added stability of the craniovertebral junction as compared with earlier reports.

METHODS Multidirectional in vitro flexibility tests were performed using a robotic spine-testing system on 7 fresh cadaveric spines to assess the effect of sequential unilateral joint-sparing condylectomy $(25 \%, 50 \%, 75 \%, 100 \%)$ in comparison with the intact state by using cardinal direction and coupled moments combined with a simulated head weight "follower load."
\end{abstract}

RESULTS The percent change in range of motion following sequential condylectomy as compared with the intact state was $5.2 \%, 8.1 \%, 12.0 \%$, and $27.5 \%$ in flexion-extension (FE); $8.4 \%, 14.7 \%, 39.1 \%$, and $80.2 \%$ in lateral bending (LB); and $24.4 \%, 31.5 \%, 49.9 \%$, and $141.1 \%$ in axial rotation (AR). Only values at $100 \%$ condylectomy were statistically significant ( $\mathrm{p}<0.05$ ). With coupled motions, however, $-3.9 \%, 6.6 \%, 35.8 \%$, and $142.4 \%$ increases in AR+F and $27.3 \%$, $32.7 \%, 77.5 \%$, and $175.5 \%$ increases in $A R+E$ were found. Values for $75 \%$ and $100 \%$ condyle resection were statistically significant in $\mathrm{AR}+\mathrm{E}$.

CONCLUSIONS When tested in the traditional cardinal directions, a 50\% joint-sparing condylectomy did not significantly increase motion. However, removing $75 \%$ of the condyle may necessitate fusion, as a statistically significant increase in motion was found when $E$ was coupled with AR. Clinical correlation is ultimately needed to determine the need for OC fusion.

https://thejns.org/doi/abs/10.3171/2016.7.JNS16293

KEY WORDS occipital condylectomy; biomechanics; skull base surgery; spine; far lateral approach; occipitocervical fusion; spinal instability

$\mathrm{A}$ NTERIOR and anterolateral lesions at the craniovertebral junction (CVJ) pose a surgical challenge to neurosurgeons given the lesions' proximity to critical neurovascular structures. Initial attempts to address such lesions from a traditional midline suboccipital craniectomy resulted in high morbidity and mortality. ${ }^{14,22,38,40}$ Over the last several decades, alternative approaches have been developed to address these lesions more safely. ${ }^{1-3,5-13,15-19,21,23-26,29,30,32-37,44}$
In 1978, Seeger first proposed removing the condyle to access the ventral foramen magnum from a more lateral approach. ${ }^{34}$ Since then, many reports in the literature have described the far lateral transcondylar and extreme lateral approaches. ${ }^{1-3,6,7,11,16,23,30,33,36,37,44}$ As these approaches became more commonplace, questions arose regarding the stability of the CVJ after condylectomy. In 1999, Vishteh et al. performed a biomechanical analysis of the CVJ after unilateral condylectomy. ${ }^{41}$ They found that removing $50 \%$

ABBREVIATIONS $\mathrm{AR}=$ axial rotation; $\mathrm{CVJ}=$ craniovertebral junction; $\mathrm{FE}=$ flexion-extension; $\mathrm{HWL}=$ head weight load; $\mathrm{LB}=$ lateral bending; $\mathrm{O}=\mathrm{occiput} ; \mathrm{OC}=\mathrm{occipito}-$ cervical; $\mathrm{ROM}=$ range of motion; $\mathrm{SOC}+\mathrm{C} 1$ = suboccipital craniectomy with $\mathrm{C}-1$ laminectomy.

SUBMITTED February 5, 2016. ACCEPTED July 29, 2016.

INCLUDE WHEN CITING Published online October 14, 2016; DOI: 10.3171/2016.7.JNS16293. 
or more of the condyle resulted in significantly increased mobility in flexion-extension (FE), lateral bending (LB), and axial rotation (AR). They concluded that occipitocervical (OC) fusion should be considered after resecting $50 \%$ or more of the condyle.

Anatomical studies have demonstrated that, on average, the hypoglossal canal divides the condyle in half along its longitudinal axis. ${ }^{4,27,28}$ Consequently, the hypoglossal canal has been used as a surgical landmark to approximate resection of $50 \%$ of the condyle. In practice, however, fusion after resection of the condyle up to the hypoglossal canal has frequently not been necessary. This clinical experience creates discordance with previous biomechanical findings. The reason for this may be 2-fold. First, because the transcondylar approach has been used and refined over time, many authors believe that the superomedial portion of the condyle obstructs visualization of the clivus and that the removal of only this portion is necessary to access most lesions of the CVJ. Condylectomy performed in a prior study by Vishteh et al. included resection of the occiput (O)-C1 joint ${ }^{41}$ Second, the results of this prior biomechanical study have not been confirmed. The authors used a quasi-static testing model that employed cables and pulleys. A biomechanical study employing dynamic testing controlled by robotics could yield different results. Therefore, we sought to assess the stability of the $\mathrm{O}-\mathrm{C} 1$ and $\mathrm{C} 1-2$ joints after unilateral joint-sparing condylectomy $(25 \%, 50 \%, 75 \%, 100 \%)$ in comparison with the intact state by using a simulated head weight, follower load, and coupled motions. We hypothesized that the joint-sparing condylectomy would result in added stability of the CVJ as compared with earlier reports.

\section{Methods \\ Cadaveric Specimens}

Seven fresh-frozen, unembalmed, human cadaveric specimens, $\mathrm{O}-\mathrm{C} 7$, free from any craniocervical pathology were used. Specimens were obtained from donors 40-75 years of age at the time of death. Donors were screened for any history of cancer or rheumatoid disease. Occipitocervical radiographs of the specimens were reviewed to rule out any traumatic injuries, fusion, prior surgery, or major deformity. The cranium was transected just above a line drawn from the supraorbital rim to the inion, and all soft tissues and musculature were removed while preserving all joint capsules and spinal ligaments. We placed 1.5$\mathrm{mm}$ titanium microscrews in various points along the $\mathrm{O}$ to serve as skull fiducial markers. Volumetric CT scanning $(1.0 \mathrm{~mm})$ of all specimens was performed for input into stereotactic navigation software (Medtronic StealthStation S7). Specimens were warmed to room temperature, and all testing for a given specimen was performed on a single day to avoid repeated freezing and thawing. Specimens were moistened with saline as needed to prevent drying during testing.

\section{Biomechanical Testing}

In vitro intact flexibility tests were conducted using a 6-axis robotic spine-testing system (KR16, Kuka Robotics). A 6-axis force-moment sensor (Delta/SI-330-30, ATI
Industrial Automation) was used to measure the applied loads and provide feedback for the robot, which was controlled with simVITRO software (Cleveland Clinic). For this study, the system applied a constant $40-\mathrm{N}$ force for head weight simulation, followed by 3 loading and unloading cycles of continuous moment $( \pm 1.5 \mathrm{Nm})$ to simulate FE, LB, and AR. The system also simulated coupled motions involving AR with $\mathrm{E}(\mathrm{AR}+\mathrm{E})$ and $\mathrm{AR}$ with $\mathrm{F}(\mathrm{AR}+\mathrm{F})$ using \pm 1.5 -Nm magnitudes. The vertical force vector was applied in the direction of gravity regardless of the orientation of the spine. This constant vertical force was used to simulate head weight load (HWL) during cervical spine motion. The specimens were preconditioned to minimize viscoelastic effects.

Range of motion (ROM) at the $\mathrm{O}-\mathrm{C} 1$ and $\mathrm{C} 1-2$ levels was determined from the final loading cycle for each specimen. The relative vertebral motion was captured using an optoelectronic camera system (Optotrak, Northern Digital Inc.). Infrared motion sensors were placed on the $\mathrm{O}$ and the vertebral bodies of C-1 and C-2 (Fig. 1). Anatomical landmarks were then digitized to define the coordinate systems and capture relative vertebral kinematics per International Society of Biomechanics standards. ${ }^{43}$

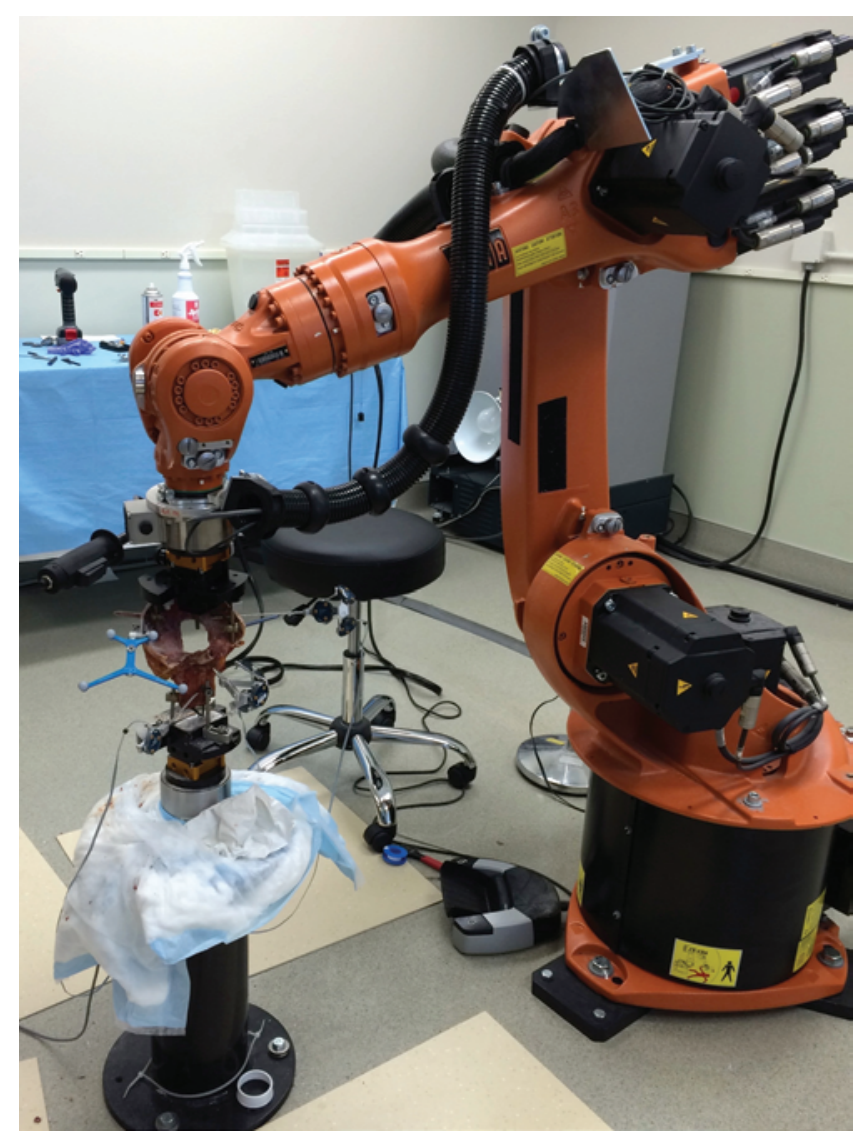

FIG. 1. Testing setup. The specimen is rigidly fixed the $O$ and C-3. A navigation reference frame is rigidly fixed to the 0 , and titanium microscrew fiducial markers are registered. Optoelectric sensors are placed in the $\mathrm{O}, \mathrm{C}-1$, and $\mathrm{C}-2$ to record relative ROM. A 6-axis robotic spinetesting system was used to apply head weight simulation and loading and unloading cycles of continuous moment. Figure is available in color online only. 

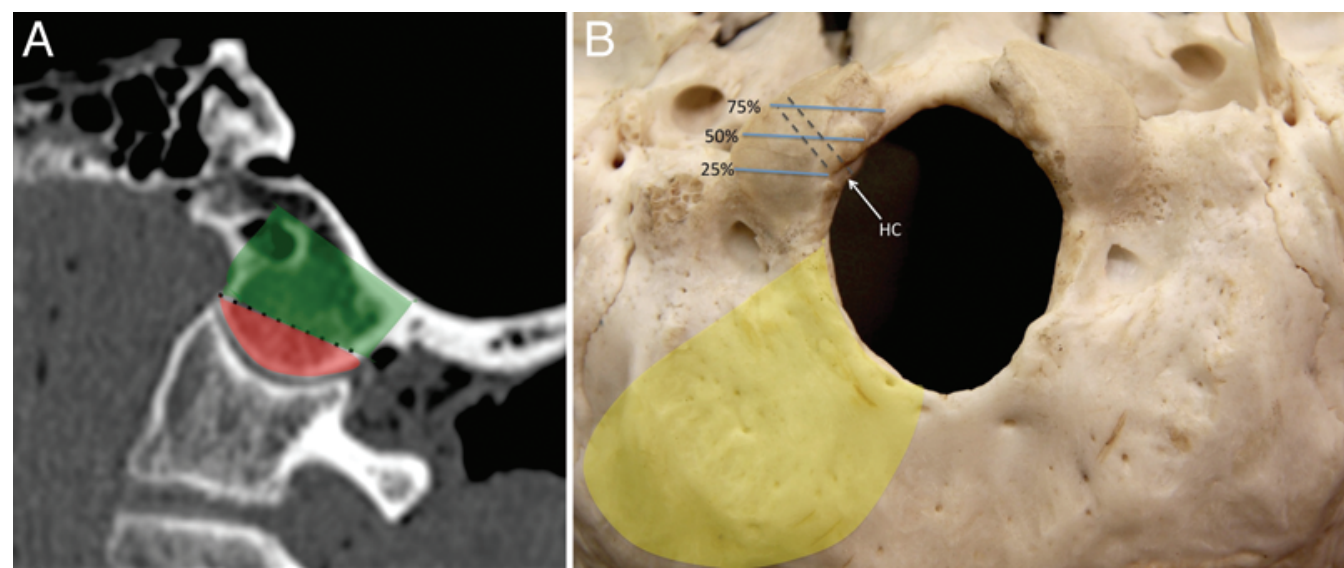

FIG. 2. A: Sagittal CT demonstrating occipital condyle anatomy with a rectangular main body (green) and concave articular surface (red). B: View of the foramen magnum. Yellow indicates the area of unilateral suboccipital craniectomy. Each condyle was divided into 4 quadrants along the anatomical transverse axis. Dotted lines indicate approximate location and course of the hypoglossal canal $(\mathrm{HC})$. Figure is available in color online only.

\section{Surgical Conditions}

First, the specimens were tested in the intact state in all planes of motion under a constant HWL. After intact testing, the following surgical conditions were sequentially performed on each specimen: unilateral suboccipital craniectomy with $\mathrm{C}-1$ laminectomy $(\mathrm{SOC}+\mathrm{C} 1)$ and $25 \%, 50 \%, 75 \%$, and $100 \%$ joint-sparing condyle resections. Cranial navigational software was used to create a condyle resection plan. The condyle was divided into 2 components: a rectangular body and a concave articulating portion. The intersection of these 2 components was defined by a line drawn from the junction of the vertical and concave portions of the condyle at its anterior and posterior aspects (Fig. 2A). The body of the condyle was divided into 4 segments along the anatomical transverse axis (Fig. 2B). Using a 2-mm diamond bur, segmental condylectomy was performed, sparing the concave articulating portion of the condyle, with the extent of the condylectomy guided by navigation (Fig. 3). With removal of the condyle body, even a $25 \%$ condylectomy, there was often very little functional attachment of the joint capsule on the posterior portion of the occipital condyle. Multidirectional flexibility testing was repeated after each sequential surgical condition. In this manner, each specimen served as its own control to account for interspecimen differences in baseline ROM.

\section{Statistical Analysis}

Mean relative ROM was compared among groups using repeated-measures ANOVA. Post hoc Tukey-Kramer analysis was used for multiple comparisons between groups. A p value $<0.05$ was considered statistically significant. Mean values are expressed with their standard deviations.

\section{Results}

\section{Intact State and C-1 Laminectomy}

The mean ROM at the OC junction in FE, LB, and AR was $24.8^{\circ} \pm 10.1^{\circ}, 6.7^{\circ} \pm 2.3^{\circ}$, and $6.9^{\circ} \pm 3.9^{\circ}$, respectively.
Coupled AR+E resulted in a mean ROM of $7.4^{\circ} \pm 4.2^{\circ}$. Coupled AR+F resulted in a mean ROM of $5.6^{\circ} \pm 2.5^{\circ}$. Unilateral $\mathrm{SOC}+\mathrm{C} 1$ resulted in no statistically significant changes (Table 1).

\section{Sequential Joint-Sparing Condylectomy}

Twenty-five percent condylectomy resulted in nonsignificant changes in ROM in all cardinal and coupled directions. Compared with the intact condition, $\mathrm{AR}+\mathrm{E}$ showed the largest absolute increase $\left(2.1^{\circ}\right)$. Mean ROM changed by only $1.3^{\circ}, 0.6^{\circ}, 1.7^{\circ}$, and $-0.2^{\circ}$ in FE, $\mathrm{LB}, \mathrm{AR}$, and $\mathrm{AR}+\mathrm{F}$. With $50 \%$ resection of the unilateral condyle, $\mathrm{AR}+\mathrm{E}$ showed a marginal increase by an additional $0.4^{\circ}$. As compared with the previous condition, $50 \%$ condylectomy resulted in a negligible change in all directions: $0.7^{\circ}$, $0.4^{\circ}, 0.5^{\circ}$, and $0.5^{\circ}$ in $\mathrm{FE}, \mathrm{LB}, \mathrm{AR}$, and $\mathrm{AR}+\mathrm{F}$, respectively.

With $75 \%$ condylectomy, the change in absolute ROM in each cardinal direction was larger than with prior surgical conditions: $1.0^{\circ}, 1.6^{\circ}, 1.3^{\circ}, 1.7^{\circ}$, and $3.3^{\circ}$ in $\mathrm{FE}, \mathrm{LB}$, $\mathrm{AR}, \mathrm{AR}+\mathrm{F}$, and $\mathrm{AR}+\mathrm{E}$, respectively. The change in $\mathrm{AR}+\mathrm{E}$ was statistically significant $(\mathrm{p}=0.04)$. The $2.6^{\circ}$ increase in ROM in LB as compared with the intact state was not significant $(\mathrm{p}=0.07)$; however, the increase was significant when evaluating LB ROM over O-C2 ( $=0.02$; Table 2). Although changes in other directions were not statistically significant, these increases were found to be 1.3-3.3 times larger than increases in ROM recorded after prior surgical conditions. As expected, there were large changes in ROM following $100 \%$ condylectomy in cardinal and coupled directions (Fig. 4).

\section{C1-2 Stability}

The mean ROM in FE, LB, AR, AR+F, and AR+E was $12.0^{\circ}, 4.9^{\circ}, 65.4^{\circ}, 64.8^{\circ}$, and $63.5^{\circ}$, respectively. There were no statistically significant changes in the ROM at C1-2 following each surgical procedure (Table 3).

\section{Measurement Variability}

Across all specimens and conditions, at the distinct 

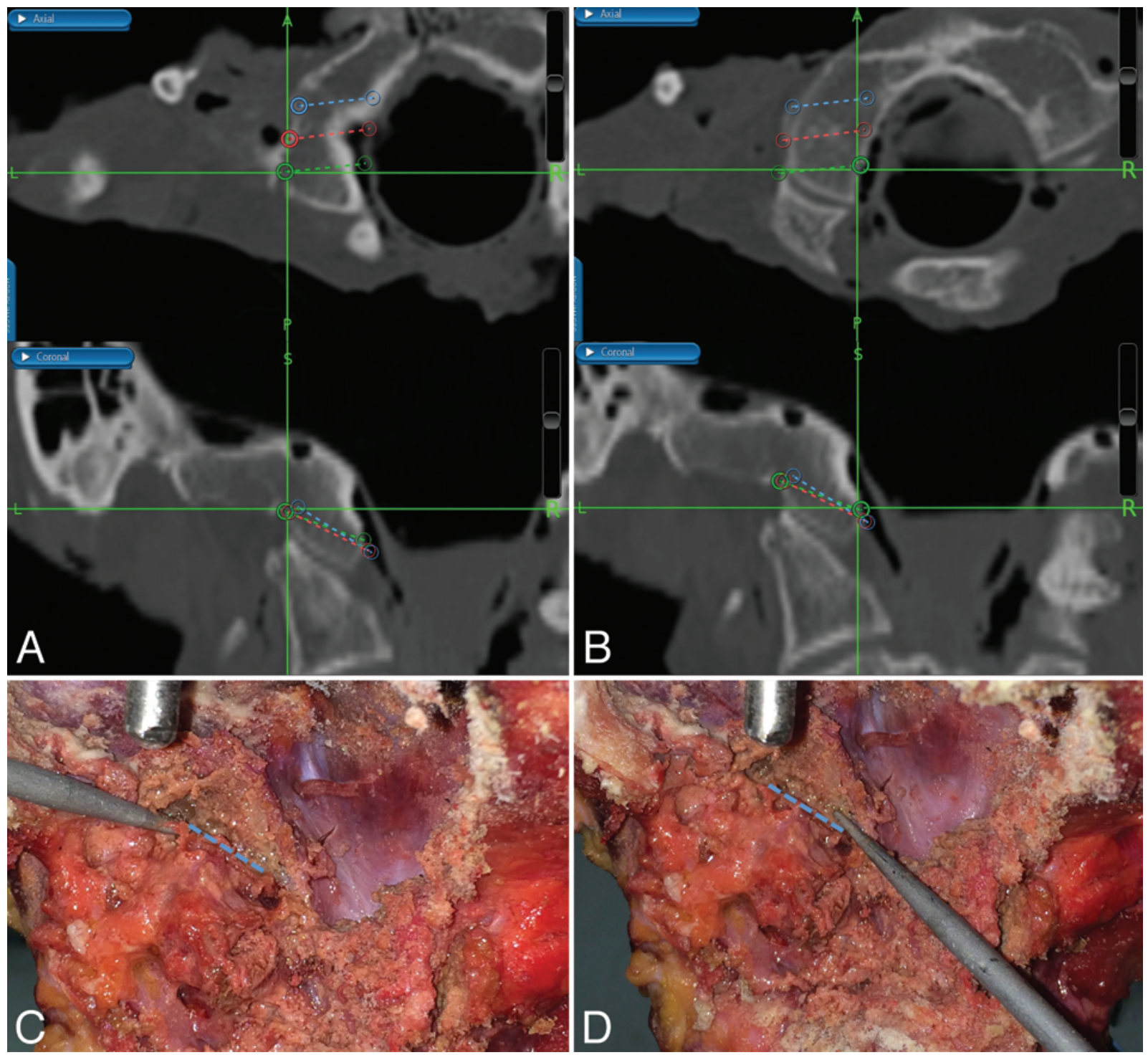

FIG. 3. Stereotactically guided joint-sparing condylectomy. Navigation plan (A and B) demonstrating $25 \%$ (green), $50 \%$ (red), and $75 \%$ (blue) resection lines. Navigation pointer on the lateral margin (C) and the medial margin (D) of the $25 \%$ condylar resection line. Blue dotted lines in the photographs (C and $\mathrm{D}$ ) indicate the posterior $\mathrm{O}-\mathrm{C} 1$ joint. Figure is available in color online only.

quasi-static loading region of interest, the root-meansquare errors between the prescribed and actual loads were $2.1 \mathrm{~N}, 9.4 \mathrm{~N}, 2.9 \mathrm{~N}, 0.08 \mathrm{Nm}, 0.04 \mathrm{Nm}$, and 0.08 $\mathrm{Nm}$ in the posterior, compression, lateral, AR, FE, and LB degrees of freedom.

\section{Discussion}

We investigated the kinematics of the OC junction following sequential joint-sparing condylectomy and found statistically significant increases in coupled ROM at the $75 \%$ condyle resection. Authors of an early biomechanical study found that condylectomy extending into the $\mathrm{OC}$ joint resulted in statistically increased FE ROM at the $25 \%$ condylectomy and larger increases in all cardinal directions after a $50 \%$ condylectomy. ${ }^{36}$ They concluded that OC fusion should be considered following $50 \%$ condyle resection. However, in an attempt to avoid iatrogenic instability requiring $\mathrm{OC}$ fusion, many surgeons perform condylectomy sparing the OC joint. ${ }^{18,19,39}$ We hypothesized that a joint-sparing technique would result in added stability at this degree of condyle resection.

In a prior study, Vishteh et al. found statistically significant increases in FE (15.3\%), LB (40.8\%), and AR (28.1\%) after resecting $50 \%$ of the condyle. ${ }^{41}$ We found smaller overall increases $(8.1 \%, 14.7 \%$, and $31.5 \%$, respectively), which were not statistically significant. This finding suggests that the joint-sparing condylectomy provides biomechanically relevant additional stability to the OC joint. In contrast to the conclusion of Vishteh et al., our data suggest that OC fusion is unlikely to be necessary when $50 \%$ of the condyle has been removed using the joint-sparing technique. At $75 \%$ condyle resection, there appeared to be meaningful increases in ROM in LB (39.1\%), but they were not significant $(\mathrm{p}=0.07)$. However, when analyzing 
TABLE 1. Occiput-C1 mean ROM in primary and coupled movements across various surgical conditions

\begin{tabular}{|c|c|c|c|c|c|c|}
\hline \multirow[b]{2}{*}{ Direction } & \multirow[b]{2}{*}{ Intact } & \multirow[b]{2}{*}{$\mathrm{SOC}+\mathrm{C} 1$} & \multicolumn{4}{|c|}{ Condyle Resection } \\
\hline & & & $25 \%$ & $50 \%$ & $75 \%$ & $100 \%$ \\
\hline $\mathrm{FE}$ & $24.8^{\circ} \pm 10.1^{\circ}$ & $\begin{array}{l}24.7^{\circ} \pm 8.4^{\circ} \\
-0.4 \%(0.49)\end{array}$ & $\begin{array}{c}26.1^{\circ} \pm 7.9^{\circ} \\
5.2 \%(0.40)\end{array}$ & $\begin{array}{r}26.8^{\circ} \pm 8.1^{\circ} \\
8.1 \%(0.34)\end{array}$ & $\begin{array}{l}27.8^{\circ} \pm 8.9^{\circ} \\
12.0 \%(0.28)\end{array}$ & $\begin{array}{l}31.6^{\circ} \pm 10.9^{\circ} \\
27.5 \%(0.12)\end{array}$ \\
\hline LB & $6.7^{\circ} \pm 2.3^{\circ}$ & $\begin{array}{r}6.7^{\circ} \pm 2.9^{\circ} \\
-0.9 \%(0.48)\end{array}$ & $\begin{array}{l}7.3^{\circ} \pm 2.8^{\circ} \\
8.4 \%(0.35)\end{array}$ & $\begin{array}{r}7.7^{\circ} \pm 2.7^{\circ} \\
14.7 \%(0.24)\end{array}$ & $\begin{array}{r}9.3^{\circ} \pm 3.8^{\circ} \\
39.1 \%(0.07)\end{array}$ & $\begin{array}{l}12.1^{\circ} \pm 5.1^{\circ} \\
80.2 \%(0.01)\end{array}$ \\
\hline AR & $6.9^{\circ} \pm 3.9^{\circ}$ & $\begin{array}{r}7.9^{\circ} \pm 4.0^{\circ} \\
13.6 \%(0.34)\end{array}$ & $\begin{array}{c}8.6^{\circ} \pm 3.6^{\circ} \\
24.4 \%(0.23)\end{array}$ & $\begin{array}{r}9.1^{\circ} \pm 4.0^{\circ} \\
31.5 \%(0.18)\end{array}$ & $\begin{array}{c}10.4^{\circ} \pm 5.1^{\circ} \\
49.9 \%(0.11)\end{array}$ & $\begin{array}{c}16.7^{\circ} \pm 6.6^{\circ} \\
141.1 \%(<0.01)\end{array}$ \\
\hline$A R+F$ & $5.6^{\circ} \pm 2.5^{\circ}$ & $\begin{array}{r}6.2^{\circ} \pm 2.3^{\circ} \\
10.9 \%(0.33)\end{array}$ & $\begin{array}{c}5.4^{\circ} \pm 2.6^{\circ} \\
-3.9 \%(0.44)\end{array}$ & $\begin{array}{l}5.9^{\circ} \pm 2.8^{\circ} \\
6.6 \%(0.41)\end{array}$ & $\begin{array}{r}7.6^{\circ} \pm 4.1^{\circ} \\
35.8 \%(0.17)\end{array}$ & $\begin{array}{c}13.5^{\circ} \pm 6.0^{\circ} \\
142.4 \%(<0.01)\end{array}$ \\
\hline$A R+E$ & $7.4^{\circ} \pm 4.2^{\circ}$ & $\begin{array}{c}8.9^{\circ} \pm 5.7^{\circ} \\
20.2 \%(0.31)\end{array}$ & $\begin{array}{c}9.5^{\circ} \pm 4.7^{\circ} \\
27.3 \%(0.24)\end{array}$ & $\begin{array}{r}9.9^{\circ} \pm 4.8^{\circ} \\
32.7 \%(0.20)\end{array}$ & $\begin{array}{l}13.2^{\circ} \pm 5.6^{\circ} \\
77.5 \%(0.04)\end{array}$ & $\begin{array}{c}20.5^{\circ} \pm 10.2^{\circ} \\
175.5 \%(0.01)\end{array}$ \\
\hline
\end{tabular}

Values reflect mean ROM \pm standard deviation (first line) and the percentage change in ROM with associated $p$ values in parentheses (second line) for each surgical condition. Boldface type indicates statistical significance $(p<0.05)$ as compared to the intact state.

the $\mathrm{ROM}$ over $\mathrm{O}-\mathrm{C} 2$, there was a significant increase $(\mathrm{p}=$ 0.02 ) in LB after $75 \%$ resection. There also appeared to be a meaningful increase in AR (49.9\%) after $75 \%$ resection, but it was not significant $(\mathrm{p}=0.11)$, probably because of power limitation. The importance of testing coupled motions was evident at this extent of condyle resection. We found a statistically significant $77.5 \%$ increase in $A R+E(p$ $=0.04$ ) following $75 \%$ condyle resection. Our results indicated that in using a joint-sparing technique, the OC joint may require fusion when $75 \%$ of the condyle is resected.

The differences in our results compared with those of the prior biomechanical study by Vishteh et al. are likely multifactorial. ${ }^{41}$ First, the joint-sparing condylectomy retains the entire OC joint surface and as much capsule as possible. Clinically, surgeons often resect the condyle to the hypoglossal canal without the need for OC fusion. Retention of this joint surface likely provides added stability as we have seen in biomechanical studies addressing partial joint resection following cervical foraminotomy. The study by Zdeblick et al. demonstrates that it is not until resection of $75 \%$ of the facet (in addition to laminectomy) that statistically significant increases in segmental displacement are seen. ${ }^{45}$ The saddle-shaped geometry of the OC joint may constrain translation to a greater extent compared with the subaxial cervical spine. Therefore, it is not surprising to find similar if not slightly greater tolerance for osseous and capsular disruption at the OC joint. Second, we used a simulated head weight, which biomechanically is a constant $40-\mathrm{N}$ load directed vertically independent of neck position. It likely loads facet joints, especially those with horizontal orientation such as the OC joint, adding to stability in a clinically relevant manner. It is worth noting that our baseline ROM in the intact specimens was similar to those in prior studies. ${ }^{31,41,42} \mathrm{We}$ found the mean ROM at $\mathrm{O}-\mathrm{C} 1$ for FE, $\mathrm{LB}$, and $\mathrm{AR}$ to be $24.8^{\circ}, 6.7^{\circ}$, and $6.9^{\circ}$. The mean and range of ROM in 4 prior studies were $25^{\circ}\left(23^{\circ}-28^{\circ}\right), 7.3^{\circ}\left(5^{\circ}-10^{\circ}\right)$, and $9.8^{\circ}$ $\left(6^{\circ}-14^{\circ}\right) .^{20,31,41,42}$

There are several important limitations to this study. First, we must acknowledge that the nomenclature for the percentage of resection does not represent the true volumetric percentage resection of the condyle. Radiographic volumetric analysis after each sequential resection was not feasible. If one divides the condyle into a superior rectangular body and an inferior concave articulating portion (Fig. 2), the percentage of condyle resection, as reported

TABLE 2. Occiput-C2 mean ROM in primary and coupled movements across various surgical conditions

\begin{tabular}{|c|c|c|c|c|c|c|}
\hline \multirow[b]{2}{*}{ Direction } & \multirow[b]{2}{*}{ Intact } & \multirow[b]{2}{*}{$\mathrm{SOC}+\mathrm{C} 1$} & \multicolumn{4}{|c|}{ Condyle Resection } \\
\hline & & & $25 \%$ & $50 \%$ & $75 \%$ & $100 \%$ \\
\hline FE & $37.9^{\circ} \pm 11.1^{\circ}$ & $\begin{array}{c}38.9^{\circ} \pm 9.4^{\circ} \\
2.5 \%(0.44)\end{array}$ & $\begin{array}{r}40.8^{\circ} \pm 9.8^{\circ} \\
7.6 \%(0.31)\end{array}$ & $\begin{array}{c}41.5^{\circ} \pm 9.7^{\circ} \\
9.5 \%(0.27)\end{array}$ & $\begin{array}{c}42.5^{\circ} \pm 9.9^{\circ} \\
12.1 \%(0.22)\end{array}$ & $\begin{array}{c}45.2^{\circ} \pm 12.3^{\circ} \\
19.1 \%(0.14)\end{array}$ \\
\hline LB & $15.3^{\circ} \pm 3.0^{\circ}$ & $\begin{array}{c}16.0^{\circ} \pm 2.4^{\circ} \\
4.4 \%(0.34)\end{array}$ & $\begin{array}{c}15.3^{\circ} \pm 1.6^{\circ} \\
0.0 \%(0.50)\end{array}$ & $\begin{array}{c}15.8^{\circ} \pm 2.1^{\circ} \\
2.8 \%(0.38)\end{array}$ & $\begin{array}{l}19.6^{\circ} \pm 3.7^{\circ} \\
27.9 \%(0.02)\end{array}$ & $\begin{array}{l}27.6^{\circ} \pm 6.6^{\circ} \\
80.1 \%(<0.01)\end{array}$ \\
\hline AR & $78.5^{\circ} \pm 11.9^{\circ}$ & $\begin{array}{c}79.2^{\circ} \pm 12.1^{\circ} \\
0.9 \%(0.46)\end{array}$ & $\begin{array}{c}82.4^{\circ} \pm 12.4^{\circ} \\
5.0 \%(0.28)\end{array}$ & $\begin{array}{r}83.6^{\circ} \pm 12.3^{\circ} \\
6.5 \%(0.22)\end{array}$ & $\begin{array}{r}85.8^{\circ} \pm 12.9^{\circ} \\
9.3 \%(0.15)\end{array}$ & $\begin{array}{r}92.6^{\circ} \pm 14.3^{\circ} \\
18.0 \%(0.03)\end{array}$ \\
\hline$A R+F$ & $75.8^{\circ} \pm 10.8^{\circ}$ & $\begin{array}{c}77.4^{\circ} \pm 11.8^{\circ} \\
2.1 \%(0.40)\end{array}$ & $\begin{array}{c}78.7^{\circ} \pm 11.1^{\circ} \\
3.9 \%(0.31)\end{array}$ & $\begin{array}{c}79.5^{\circ} \pm 11.0^{\circ} \\
4.8 \%(0.27)\end{array}$ & $\begin{array}{r}82.0^{\circ} \pm 12.4^{\circ} \\
8.1 \%(0.17)\end{array}$ & $\begin{array}{r}89.6^{\circ} \pm 15.9^{\circ} \\
18.2 \%(0.04)\end{array}$ \\
\hline$A R+E$ & $75.6^{\circ} \pm 11.5^{\circ}$ & $\begin{array}{c}76.4^{\circ} \pm 11.6^{\circ} \\
1.0 \%(0.45)\end{array}$ & $\begin{array}{c}79.2^{\circ} \pm 11.8^{\circ} \\
4.7 \%(0.29)\end{array}$ & $\begin{array}{c}80.0^{\circ} \pm 11.8^{\circ} \\
5.8 \%(0.25)\end{array}$ & $\begin{array}{r}82.9^{\circ} \pm 11.9^{\circ} \\
9.7 \%(0.13)\end{array}$ & $\begin{array}{r}92.6^{\circ} \pm 16.4^{\circ} \\
22.5 \%(0.02)\end{array}$ \\
\hline
\end{tabular}

Values reflect mean ROM \pm standard deviation (first line) and percentage change in ROM with associated $p$ values in parentheses (second line) for each surgical condition. Boldface type indicates statistical significance $(p<0.05)$ as compared to the intact state. 


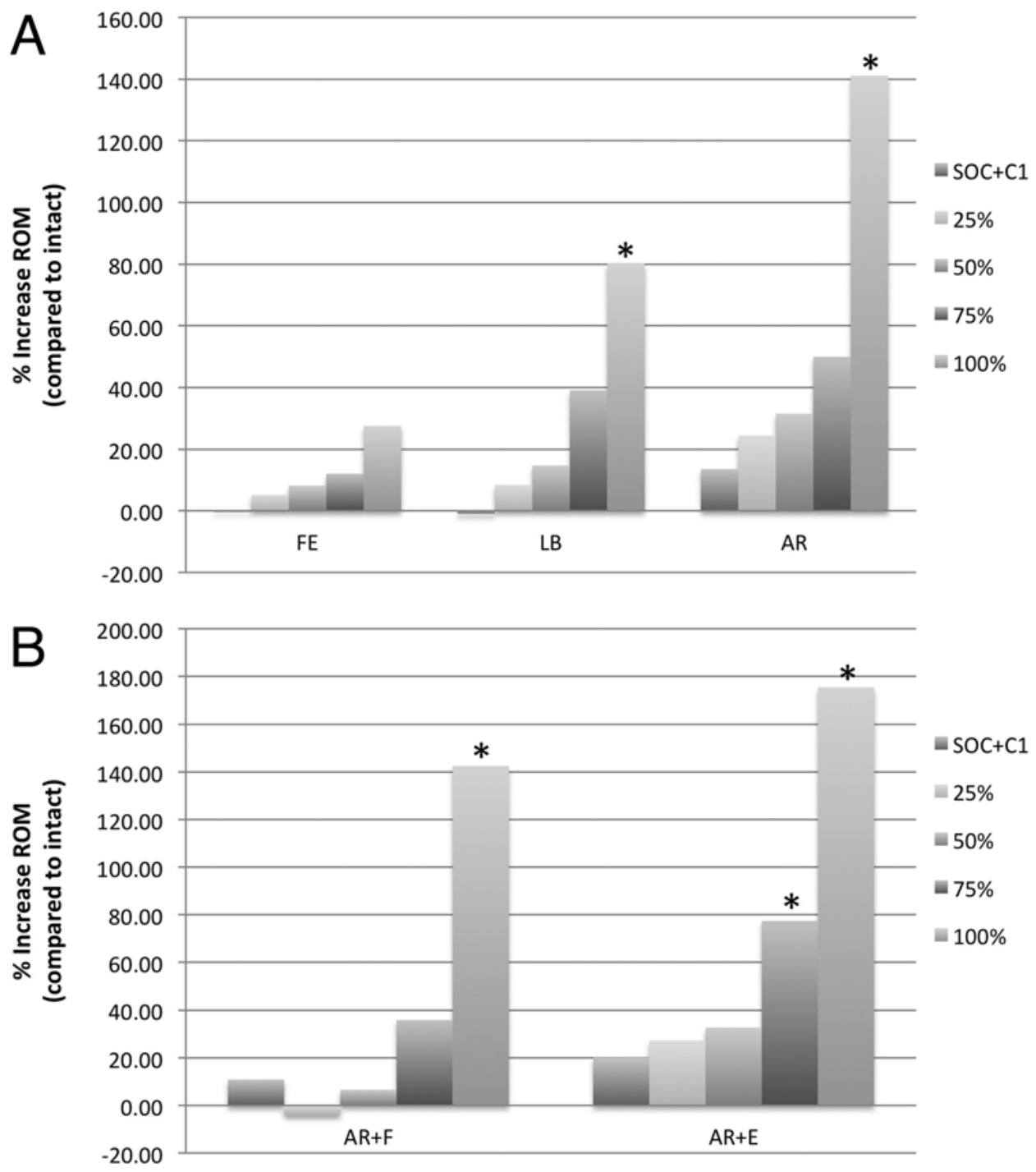

FIG. 4. Occiput-C1 mean ROM (\% change compared with intact state) in cardinal (A) and coupled (B) movements across various surgical conditions. Asterisks indicate statistical significance compared with the intact state.

TABLE 3. C1-2 mean ROM in primary and coupled movements across various surgical conditions

\begin{tabular}{|c|c|c|c|c|c|c|}
\hline \multirow[b]{2}{*}{ Direction } & \multirow[b]{2}{*}{ Intact } & \multirow[b]{2}{*}{$\mathrm{SOC}+\mathrm{C} 1$} & \multicolumn{4}{|c|}{ Condyle Resection } \\
\hline & & & $25 \%$ & $50 \%$ & $75 \%$ & $100 \%$ \\
\hline $\mathrm{FE}$ & $12.0^{\circ} \pm 4.3^{\circ}$ & $\begin{array}{c}12.2^{\circ} \pm 3.7^{\circ} \\
1.8 \%(0.46)\end{array}$ & $\begin{array}{l}13.5^{\circ} \pm 2.4^{\circ} \\
12.7 \%(0.22)\end{array}$ & $\begin{array}{c}13.7^{\circ} \pm 2.6^{\circ} \\
14.4 \%(0.19)\end{array}$ & $\begin{array}{l}13.7^{\circ} \pm 2.9^{\circ} \\
15.0 \%(0.19)\end{array}$ & $\begin{array}{c}12.9^{\circ} \pm 3.8^{\circ} \\
8.2 \%(0.33)\end{array}$ \\
\hline LB & $4.9^{\circ} \pm 2.9^{\circ}$ & $\begin{array}{l}5.2^{\circ} \pm 3.1^{\circ} \\
5.5 \%(0.44)\end{array}$ & $\begin{array}{l}5.2^{\circ} \pm 2.3^{\circ} \\
6.4 \%(0.41)\end{array}$ & $\begin{array}{c}5.3^{\circ} \pm 2.2^{\circ} \\
7.9 \%(0.39)\end{array}$ & $\begin{array}{c}5.8^{\circ} \pm 2.0^{\circ} \\
18.1 \%(0.26)\end{array}$ & $\begin{array}{c}6.4^{\circ} \pm 2.3^{\circ} \\
31.8 \%(0.14)\end{array}$ \\
\hline AR & $65.4^{\circ} \pm 9.0^{\circ}$ & $\begin{array}{l}62.8^{\circ} \pm 11.8^{\circ} \\
-4.0 \%(0.35)\end{array}$ & $\begin{array}{r}66.7^{\circ} \pm 8.8^{\circ} \\
2.0 \%(0.41)\end{array}$ & $\begin{array}{r}69.9^{\circ} \pm 9.9^{\circ} \\
6.8 \%(0.23)\end{array}$ & $\begin{array}{r}70.9^{\circ} \pm 9.9^{\circ} \\
8.4 \%(0.18)\end{array}$ & $\begin{array}{r}71.9^{\circ} \pm 9.8^{\circ} \\
9.9 \%(0.14)\end{array}$ \\
\hline$A R+F$ & $64.8^{\circ} \pm 13.3^{\circ}$ & $\begin{array}{c}63.6^{\circ} \pm 19.6^{\circ} \\
-1.8 \%(0.45)\end{array}$ & $\begin{array}{r}69.6^{\circ} \pm 11.1^{\circ} \\
7.4 \%(0.26)\end{array}$ & $\begin{array}{r}70.2^{\circ} \pm 10.8^{\circ} \\
8.4 \%(0.23)\end{array}$ & $\begin{array}{c}71.3^{\circ} \pm 10.8^{\circ} \\
10.1 \%(0.19)\end{array}$ & $\begin{array}{c}74.2^{\circ} \pm 10.4^{\circ} \\
14.5 \%(0.09)\end{array}$ \\
\hline$A R+E$ & $63.5^{\circ} \pm 10.4^{\circ}$ & $\begin{array}{l}61.3^{\circ} \pm 17.5^{\circ} \\
-3.4 \%(0.40)\end{array}$ & $\begin{array}{r}67.2^{\circ} \pm 8.7^{\circ} \\
5.9 \%(0.26)\end{array}$ & $\begin{array}{c}67.8^{\circ} \pm 8.7^{\circ} \\
6.9 \%(0.22)\end{array}$ & $\begin{array}{r}68.8^{\circ} \pm 8.4^{\circ} \\
8.4 \%(0.18)\end{array}$ & $\begin{array}{c}70.6^{\circ} \pm 10.3^{\circ} \\
11.2 \%(0.13)\end{array}$ \\
\hline
\end{tabular}

Values reflect mean $\mathrm{ROM} \pm$ standard deviation (first line) and percentage change in ROM with associated $p$ values in parentheses (second line) for each surgical condition. There were no statistically significant changes in the ROM at C1-2 following each surgical procedure. 
in our study, refers to the percentage of the superior rectangular body. Clinically, this portion of the condyle can be easily divided into 4 quadrants on an axial CT scan, and the degree of condyle resected intraoperatively can be estimated by neuronavigation. Second, while we have used standard validated biomechanical techniques, a cadaveric (nonhealing) model is limited in that we only test for acute instability and cannot assess the effect of repeated cyclical loading and unloading that, coupled with postsurgery biological remodeling, may affect ROM and contribute to chronic instability. Moreover, chronic instability may pose a greater problem with higher degrees of condylectomy (for example, $75 \%$ ) given the narrow column of bone that connects the occiput to the articulating surface of the condyle. Third, we have compared our results of the joint-sparing technique with those in similar prior biomechanical studies in which the joint was not spared. With additional resources, repeating the same study with the non-joint-sparing technique would allow more direct comparison of relative stability between these techniques and account for differences in the testing setup. Lastly, although we have compared our results to prior studies, there are no precise numerical ROM cutoffs for instability. Therefore, our results must be cautiously interpreted, and clinical symptoms must be evaluated to further assess for any signs of instability.

\section{Conclusions}

Results of this study suggest that in using a joint-sparing technique, up to $75 \%$ of the condyle can be removed without significant biomechanical instability at the $\mathrm{O}-\mathrm{C} 1$ joint necessitating fusion. Condylectomy did not result in any significant instability at $\mathrm{C} 1-2$. These results must be interpreted in the context of the study limitations and clinical symptoms.

\section{Acknowledgments}

We thank Ajit Krishnaney, MD, and Joung H. Lee, MD, for their clinical input on this project.

This study was funded by Grant No. RPC2014-1019 from the Cleveland Clinic Lerner College of Medicine Research Program Committee. Additional funding was provided by the Cleveland Clinic Stanley Zielony Spinal Surgery Research and Education Fund.

\section{References}

1. Arnautović KI, Al-Mefty O, Husain M: Ventral foramen magnum meningiomas. J Neurosurg Spine 92:71-80, 2000

2. Babu RP, Sekhar LN, Wright DC: Extreme lateral transcondylar approach: technical improvements and lessons learned. J Neurosurg 81:49-59, 1994

3. Banerji D, Behari S, Jain VK, Pandey T, Chhabra DK: Extreme lateral transcondylar approach to the skull base. Neurol India 47:22-30, 1999

4. Barut N, Kale A, Turan Suslu H, Ozturk A, Bozbuga M, Sahinoglu K: Evaluation of the bony landmarks in transcondylar approach. Br J Neurosurg 23:276-281, 2009

5. Bassiouni H, Ntoukas V, Asgari S, Sandalcioglu EI, Stolke D, Seifert V: Foramen magnum meningiomas: clinical outcome after microsurgical resection via a posterolateral suboccipital retrocondylar approach. Neurosurgery 59:1177-1187, 2006

6. Bertalanffy H, Gilsbach JM, Mayfrank L, Klein HM, Kawase T, Seeger W: Microsurgical management of ventral and ventrolateral foramen magnum meningiomas. Acta Neurochir Suppl 65:82-85, 1996
7. Bertalanffy H, Seeger W: The dorsolateral, suboccipital, transcondylar approach to the lower clivus and anterior portion of the craniocervical junction. Neurosurgery 29:815821,1991

8. Bruneau M, George B: Foramen magnum meningiomas: detailed surgical approaches and technical aspects at Lariboisière Hospital and review of the literature. Neurosurg Rev 31:19-33, 2008

9. Chotai S, Kshettry VR, Ammirati M: Endoscopic-assisted microsurgical techniques at the craniovertebral junction: 4 illustrative cases and literature review. Clin Neurol Neurosurg 121:1-9, 2014

10. Crockard HA, Sen CN: The transoral approach for the management of intradural lesions at the craniovertebral junction: review of 7 cases. Neurosurgery 28:88-98, 1991

11. David CA, Spetzler RF: Foramen magnum meningiomas. Clin Neurosurg 44:467-489, 1997

12. George B, Dematons C, Cophignon J: Lateral approach to the anterior portion of the foramen magnum. Application to surgical removal of 14 benign tumors: technical note. Surg Neurol 29:484-490, 1988

13. George B, Lot G: Anterolateral and posterolateral approaches to the foramen magnum: technical description and experience from 97 cases. Skull Base Surg 5:9-19, 1995

14. Guidetti B, Spallone A: Benign extramedullary tumors of the foramen magnum. Surg Neurol 13:9-17, 1980

15. Heros RC: Lateral suboccipital approach for vertebral and vertebrobasilar artery lesions. J Neurosurg 64:559-562, 1986

16. Kratimenos GP, Crockard HA: The far lateral approach for ventrally placed foramen magnum and upper cervical spine tumours. Br J Neurosurg 7:129-140, 1993

17. Kshettry VR, Benzel EC: Endoscopic-assisted techniques at the craniovertebral junction: understanding indications and limitations. World Neurosurg 82:e711-e712, 2014

18. Kshettry VR, Chotai S, Chen W, Zhang J, Ammirati M: Quantitative analysis of the effect of brainstem shift on surgical approaches to anterolateral tumors at the craniovertebral junction. J Clin Neurosci 21:644-650, 2014

19. Kshettry VR, Chotai S, Hou J, Lamki T, Ammirati M: Successful resection of anterior and anterolateral lesions at the craniovertebral junction using a simple posterolateral approach. J Clin Neurosci 21:616-622, 2014

20. Little AS, Perez-Orribo L, Rodriguez-Martinez NG, Reyes PM, Newcomb AG, Prevedello DM, et al: Biomechanical evaluation of the craniovertebral junction after inferior-third clivectomy and intradural exposure of the foramen magnum: implications for endoscopic endonasal approaches to the cranial base. J Neurosurg Spine 18:327-332, 2013

21. Lot G, George B: The extent of drilling in lateral approaches to the cranio-cervical junction area from a series of 125 cases. Acta Neurochir (Wien) 141:111-118, 1999

22. Love JG, Thelen EP, Dodge HW Jr: Tumors of the foramen magnum. J Int Coll Surg 22:1-17, 1954

23. Margalit NS, Lesser JB, Singer M, Sen C: Lateral approach to anterolateral tumors at the foramen magnum: factors determining surgical procedure. Neurosurgery 56 (2 Suppl):324-336, 2005

24. Menezes AH, Traynelis VC, Gantz BJ: Surgical approaches to the craniovertebral junction. Clin Neurosurg 41:187-203, 1994

25. Miller E, Crockard HA: Transoral transclival removal of anteriorly placed meningiomas at the foramen magnum. Neurosurgery 20:966-968, 1987

26. Mullan S, Naunton R, Hekmat-Panah J, Vailati G: The use of an anterior approach to ventrally placed tumors in the foramen magnum and vertebral column. J Neurosurg 24:536543,1966

27. Muthukumar N, Swaminathan R, Venkatesh G, Bhanumathy 
SP: A morphometric analysis of the foramen magnum region as it relates to the transcondylar approach. Acta Neurochir (Wien) 147:889-895, 2005

28. Naderi S, Korman E, Citak G, Güvençer M, Arman C, Senoğlu M, et al: Morphometric analysis of human occipital condyle. Clin Neurol Neurosurg 107:191-199, 2005

29. Nanda A, Vincent DA, Vannemreddy PS, Baskaya MK, Chanda A: Far-lateral approach to intradural lesions of the foramen magnum without resection of the occipital condyle. J Neurosurg 96:302-309, 2002

30. Parlato C, Tessitore E, Schonauer C, Moraci A: Management of benign craniovertebral junction tumors. Acta Neurochir (Wien) 145:31-36, 2003

31. Perez-Orribo L, Little AS, Lefevre RD, Reyes PR, Newcomb AG, Prevedello DM, et al: Biomechanical evaluation of the craniovertebral junction after anterior unilateral condylectomy: implications for endoscopic endonasal approaches to the cranial base. Neurosurgery 72:1021-1030, 2013

32. Pritz MB: Evaluation and treatment of intradural tumours located anterior to the cervicomedullary junction by a lateral suboccipital approach. Acta Neurochir (Wien) 113:74-81, 1991

33. Rhoton AL Jr: The far-lateral approach and its transcondylar, supracondylar, and paracondylar extensions. Neurosurgery 47 (3 Suppl):S195-S209, 2000

34. Seeger W: Atlas of Topographic Anatomy of the Brain and Surrounding Structures. Vienna: Springer, 1978

35. Sekhar LN, Ramanathan D: Evolution of far lateral and extreme lateral approaches to the skull base. World Neurosurg 77:617-618, 2012

36. Sen CN, Sekhar LN: An extreme lateral approach to intradural lesions of the cervical spine and foramen magnum. Neurosurgery 27:197-204, 1990

37. Sen CN, Sekhar LN: Surgical management of anteriorly placed lesions at the craniocervical junction-an alternative approach. Acta Neurochir (Wien) 108:70-77, 1991

38. Smolik EA, Sachs E: Tumors of the foramen magnum of spinal origin. J Neurosurg 11:161-172, 1954

39. Spektor S, Anderson GJ, McMenomey SO, Horgan MA, Kel$\operatorname{logg}$ JX, Delashaw JB Jr: Quantitative description of the farlateral transcondylar transtubercular approach to the foramen magnum and clivus. J Neurosurg 92:824-831, 2000
40. Stein BM, Leeds NE, Taveras JM, Pool JL: Meningiomas of the foramen magnum. J Neurosurg 20:740-751, 1963

41. Vishteh AG, Crawford NR, Melton MS, Spetzler RF, Sonntag VK, Dickman CA: Stability of the craniovertebral junction after unilateral occipital condyle resection: a biomechanical study. J Neurosurg 90 (1 Suppl):91-98, 1999

42. White AA III, Panjabi MM: Clinical Biomechanics of the Spine, ed 2. Philadelphia: Lippincott Williams \& Wilkins, 1990

43. Wu G, Siegler S, Allard P, Kirtley C, Leardini A, Rosenbaum $\mathrm{D}$, et al: ISB recommendation on definitions of joint coordinate system of various joints for the reporting of human joint motion-part I: ankle, hip, and spine. J Biomech 35:543548,2002

44. Wu Z, Hao S, Zhang J, Zhang L, Jia G, Tang J, et al: Foramen magnum meningiomas: experiences in 114 patients at a single institute over 15 years. Surg Neurol 72:376-382, 2009

45. Zdeblick TA, Zou D, Warden KE, McCabe R, Kunz D, Vanderby R: Cervical stability after foraminotomy. A biomechanical in vitro analysis. J Bone Joint Surg Am 74:22-27, 1992

\section{Disclosures}

Mr. Colbrunn receives royalties from the Cleveland Clinic Foundation Innovations Department.

\section{Author Contributions}

Conception and design: Kshettry. Acquisition of data: Kshettry, Healy, Colbrunn, Beckler. Analysis and interpretation of data: Kshettry, Healy, Colbrunn. Drafting the article: Kshettry. Critically revising the article: all authors. Reviewed submitted version of manuscript: all authors. Approved the final version of the manuscript on behalf of all authors: Kshettry. Study supervision: Benzel, Recinos.

\section{Correspondence}

Varun R. Kshettry, Department of Neurological Surgery, Neurological Institute, Cleveland Clinic, 9500 Euclid Ave., S-40, Cleveland, OH 44195. email: varunkshettry@gmail.com. 